resistance. Simultaneously with, or even before, the occurrence of these symptoms, the increased elimination of alcohol commences; and one can scarcely doubt that this is due to vaso-motor paralysis, allowing distension of small vessels and an increased excretion of water, carrying with it an accidental excess of alcohol, which betrays itself to the discrimination of the chromic acid $t$ st. On this supposition the discovery of a notable excess of alcohol in the urine above that observed in the case of healthy and temperate persons, may be reasonably supposed to mark the first stage of the poisonous action of alcohol. And, if this be true, its value as an indication for the omission or diminution of the wine or brandy must be considered very great. It is a far more accurate test of a harmful action of alcohol than mere increase of pulse-frequency; for this may be due to natural phenomena of the disease.

I think the adoption of a purely chemical test like this, and of a purely physical test like the estimation of arterial tension by the sphygmograph, would be very much more likely to settle the dispute as to what is the proportion of cases of acute disease in which alcohol is useful, and what are the doses which are appropriate to particular stages of the disease, than any other kind of investigation. But, indeed, I do not expect that any hard and fast average line can be laid down; my very case is, that every fever or pneumonia patient must be treated aecording to his own special symptoms, and that these symptoms must be appreciated by accurate methods of observation. Such phenomena as mere redness or heat of skin, which some rely on, are simply no indications whatever, either for or against alcohol, until it has been tried. Greatly lowered arterial tension is a rational indication for alcohol; and if the experimental administration of the latter heightens tensior, the treatment will be sanctioned pro tempore. And if the first twenty-four hours' urine gives only the signs of minute elimination of alcohol the sanction will be confirmed. On a future occasion I shall endeavour to show that the statistical arguments which are frequently brought forward against the use of alcohol in acute disease are of necessity misleading, and are infected with sources of fallacy which render them valueless.

Wimpole-street, Jan. 1868.

\section{A CASE OF PIROGOFF'S AMPUTATION AT THE ANKLE, WITH A NEW FORM OF ARTIFICIAL FOOT.}

\section{BY CHRISTOPHER HEATH, F.R.C.S.,}

ASSISTANT-SURGEON TO UNIVERSITX COLLEGE HOSPITAL, AND TEACHER ON OPRRATIVE SURGERY IN UNIVERSITY COLLEGE, LONDON.

The following case of chronic disease of the foot, ending in amputation, illustrates the various phases which the disease may undergo, and the illusory hopes of cure without operation which may from time to time sustain both the patient and the surgeon. In selecting Pirogoff's amputation as the final remedy, I was infuenced by my experience of the admirable results which that operation affords in cases where the os calcis is sound, and the ease with which the operation itself is performed. Without depreciating Mr. Syme's operation, which, when done in strict accordance with his directions, answers admirably, I am convinced that Pirogoff's is the easier proceeding, and that, when properly performed, the result is incomparably better than after Chopart's amputation, the shortened foot of which is an inconvenience both to the patient and the instrument-maker, who has diffeulty in obviating pressure upon the extensive cicatrix.

In the performance of the operation, so long as the os calcis and the malleoli are cut obliquely in opposite directions (as originally propesed by Mr. Tudor), I think it a matter of no importance whether the calcaneum be sawn from above or from below, and in fact am in the habit of teaching the two methods alternately to my pupils; but in either case it is important to reflect the tissues slightly before applying the saw, so as not to leave too much bone in the flap. I much prefer opening the ankle-joint to removing the foot with the malleoli, as has been recommended. The amount of suppuration following the operation is exceedingly small if the cut surfaces of the bone lie in easy apposition, and especially if, as in this case, the solution of chloride of zinc, recommended by Mr. De Morgan, be employed.

Mr. H. W_, aged sixteen, came under my care in April, 1866, with well-marked disease of the transverse tarsal joint, the result of an injury to the foot two years before, which had been lighted up again by a sprain two months since. The synovial membrane of the joint was much swollen, but there was no fluid; the foot was hot and swollen, and the patient could not bear his weight upon it. I strapped the foot with twilled calico plaster, and ordered him to procure a pinleg with a support for the knee, so as to keep the foot off the ground. By the middle of May there was evident fluctuation, and I therefore had a moulded leather splint fitted to the foot, so as to keep it perfectly quiet, and opened the abscess below the external malleolus. From this incision feeble granulations sprang up, which were dressed with iodine lotion, and he took the syrup of iodide of iron. In September, after some weeks' absence in the country, three openings had formed below the inner malleolus, each of the size of a shilling. No dead bone could be detected at either side by a probe, which passed deeply between the bones of the tarsus. He now took codliver oil, and used a nitricacid lotion to the sores. Under this treatment the foot made slow but steady progress. A small piece of bone came away in November, and by February, 1867, the wounds were nearly closed, and the foot had become more shapely. The patient could bear a good deal of weight upon the foot without pain, but still employed the splint and pin-leg by my direction. Early in April, however, a swelling appeared in the sole of the foot, near the metatarsus, which 1 opened; but two other openings formed spontaneously, and the patient's health began to give way. He spent May at the seaside, but at the end of that month $I$ found a threatening of an abscess on the dorsal surface of the metatarsus. In June, though the general health had much improved, and the patient had gained weight, his foot was worse, all the old sinuses having reopened, and a fresh one formed on the inner side. The swelling orer the metatarsus had not increased; but a fresh point of fluctuation was present on the inner side, near the ankle-joint. No grating was present in the joints. Under these circumstances, I requested a consultation with $\mathrm{Mr}$. Erichsen, who entirely agreed with me as to the propriety of an immediate operation

I performed Pirogoft's amputation on the 15th June, with Mr. Erichsen's assistance, opening the ankle-joint, and sawing the calcaneum from above in a slanting direction. At one part the cut surface looked a little congested, and I therefore took a second slice. The surface of the wound was bathed with a solution of chloride of zinc (forty grains to the ounce), and the flap came readily into apposition, being retained by a few sutures, and a strap of plaster beneath the heel.

The foot after removal showed advanced disease between the astragalus and scaphoid bone, but little between the calcaneum and cuboid. The ankle-joint was healthy, except that the articular cartilage of the astragalus was discoloured on one side, opposite the last-formed abscess. There was a large abscess above and below the metatarsal bones, two of which were bare.

Mr. W- made an uninterruptedly good recovery, and was able to go on to the sofa on the tenth day. On the twelfth day he stood up and walked a few steps, with the limb supported on his old pin-leg. A fortnight after the operation he went to a relative's house at Ealing, a part of the incision having skinned over, and the remainder having granulated healthily. On the 2nd July I found him greatly improved in personal appearance, and the wound making good progress but a small abscess had formed an inch above the healed in. cision on the inner side, which I opened. By the end of the month the wound was quite healed, and the stump perfectly sound and able to bear any pressure; but the sinus remaining from the abscess still slightly discharged. He returned to his home in the country, and came up in November to see about an artificial toot, which Mr. Pratt, of Oxford-street, contrived with great skill, so as to obviate the unsightly thickening of the ankle often seen in apparatuses of the kind, the foot at the same time being light and inexpensive, and enabling the wearer to walk in an easy and natural manner.

The apparatus (Fig. I) consists of a leather socket, carefully moulded to the lower part of the limb, well lined, and made to lace up the front; the round aperture shown in the drawing being made to obviate any pressure on the site of the sinus 
already described. The foot part is made of soft padded

FIG. 1.

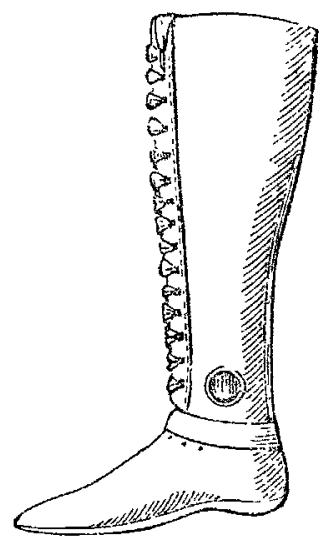

Fig. 2.

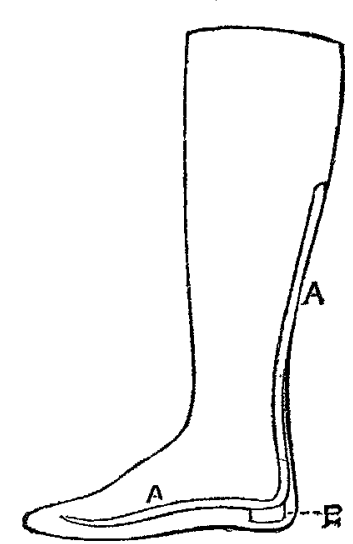

leather, so that a boot may be easily drawn over it, and its softness does away with the uncomfortable "wooden-leg feel" sometimes experienced by a living foot on coming in contact with an artificial one. The sole is made of stout leather, and from it a double spring (Fig. 2, A) passes beneath the foot and behind the leg, to be attached to the socket. This gives ample elasticity in walking, and prevents the toe catching on the ground; whilst a pad of thick india-rubber (B) beneath the heel prevents any shock being transmitted from that part.

Cavendish-place, January, 1868.

\section{SOME CONTRIBUTIONS}

\section{PATHOLOGY OF FIBROUS TUMOURS.}

By J. H. JAMES, F.R.C.S., \&c.,

FORMERLY CONSULTING SURGEON TO THE DEVON AND EXETER HOSPITAL AND DISPENSARY.

(Concluded from page 44 .)

THE preceding group consists of cases remarkably resembling each other in many important respects, and, as relating to the surgery of the disease, deserves especial attention. But fibrous tumours of similar intrinsic characters occur where they are neither complicated with muscle, tendon, or bone, or contiguous to arteries of first-rate importance. They are found in the midst of glandular structure, as in the parotid and mamma, of which the two following are examples :-

CASE 9.-A girl, aged seventeen, who was under the care of my friend and colleague, Mr. Kempe, had a tumour evidently imbedded in the parotid. It was removed on April 29th, 1863, with a considerable atmosphere of gland, with which its capsule was intimately connected. Its section showed a dense white homogeneous surface, similar to the cases already related.

I apprehend that these tumours, when situated in the parotid gland, have been denominated "parotid tumours," as if they were a distinct species; but I would beg to refer to Case 4, where a tumour, similar in all essentials, was situated under the jaw, in the midst of muscular structure, and in close contact with the pharynx.

CASE 10.-A healthy young woman had a tumour about the size of a small marble, oblong, situated in the upper part of the left breast. It was very free, and gave the idea of a fibrous tumour. I operated on August 22nd, 185\%. Of course there was no intertion of removing the mamma. It was found imbedded in the gland. It had a distinct capsule, and its section was nearly white and solid. The preparation is in the museum.

These two cases are given merely to show that fibrous tumours, precisely similar in character to those in the first group, occur in glandular structure, quite independent of any other condition, but may be modified in some slight degree by the influence of adjoining tissue, a circumstance which, I believe, applies to all tumours. I have seen the tumours, probably originating in gland, extend themselves to the neighbouring muscular structure: thus, from the parotid to the masseter muscle, in a case operated upon by Mr. Kempe on May 18th, 1861.

In addition to pure fibrous tumours, we have them variously combined, but especially as fibro-cystic. These are frequent in the female, as in the mamma, ovaries, and uterus; also in the male, as in the testes. But it would be superfluous in me to offer any observation on a class of tumours which have been so well described of late. I must, however, be permitted to indulge in a very natural wish to make a well-deserved mention of a son, who had begun a most promising career, to be ended but too soon. The case was one of an immense fibro-cystic sarcoma, occupying a large portion of the external and internal lower region of the pelvis in the person of a girl, aged twelve, and stated to have existed from birth. There was no pain, but great discomfort; no impediment to the passing of the frces. An oval incision removed a portion of the skin on the external part. There was some difficulty in dissecting it off the adjacent skin where pressure had caused it to adhere ; in other places, where fat had interposed, it was easy. The tumour was attached to both sacro-sciatic ligaments, but chiefly to the left. It had passed into the pelvis extensively, and protruded the os coccygis largely. It lay in close contact with the rectum, from which it was dissected, and when removed left an enormous chasm. To the wet preparation preserved in the museum, the following description is appended :- "That it was included in a complete external case of fibro-membranous envelope. Internally, there were many cysts enclosed in a thick fibro-membranous case. Within these were the most varied substances. One contained a large quantity of fluid, resembling red currant jelly and water, which sprung out when the cyst was punctured. One contained a considerable quantity of green, glairy fluid. One contained a fuid resembling thick glairy pus. Several small ones not opened. There was a mass of dense fibrous structure ; another mass consisting of what closely resembled cartilage of ossification. The matrix varied a good deal, but was of a mixed fibrous and adipose structure." She perfectly recovered.

The measurement of the cast taken before the operation was as follows :-Circumference, eighteen inches; greatest length from left to right, nine inches; transverse, eight inches.

I need not say that to have removed a tumour of such dimensions, and so situated, without wounding the intestine, which was so largely bared, or the arteries which cluster around the sacro-sciatic ligaments, required no little dexterity. I shall only remark that it must be a question where this tumour originated. I have notes of others which were under the care of some of my iriends, and seem to have sprung from the tuber ischii or the ligament, and I suspect this must have originated. in a similar situation.

It would be superfluous to offer any observations on the general diagnosis of fibrous tumours, so much has been lately done, and so ably. But in illustration of the diagnosis of this particular class with which we have been engaged, I will offer a few remarks, because it is clear to me that if their diagnosis had been generally understood, we should not see so many cases of the gravest description allowed to attain such a size, when their removal involves the most serious risk of life, or may be an impossibility. I am satisfied that the cause has been, that they have been mistaken for scrofulous glands ; althougi so many circumstances denote the nature of the latter that, if fully investigated, the mistake could hardly occur. For constitution generally shows the character; so does the fact that the swellings are often multiple; so does the other fact, that scrofulous glands frequently vary in size, which these tumours never do, but to increase. The deep connexions of these tumours, when at all large, also indicate their nature.

It may be right to offer a few further remarks with regard to the capsular investments of fibrous tumours. They form a very important part of their organisation; they, together with the globular character of the tumours, constitute the ordinary distinction between fibrous tumours and cancers; they seem to limit the influence of the fibrous tumour, while the absence of any such limit in cancer allows them to taint all the surrounding tissues to an indefinite extent; and in proportion as the capsule is more or less perfect, it appears to me, is the probability of the disease being localised. The exact relation of these capsales to the substance of the tumour within, and also to the tissues without, with which they are connected, may perhaps have been specially described, but I am not aware of the fact. Their removal with the tumour at all events ought to bo complete. The capsules of fibrons difier widely from those containing some other tumours, as the adipose, which may be easily shelled out; while, with respect to these, the contiguous tissues should always be removed with them, although to a small extent only. It may also be right to observe, that in many of these cases the capsules are not only in close juxtaposition with large vessels, but are very vascular 